\title{
Vitamin D is associated with cardiopulmonary exercise capacity: results of two independent cohorts of healthy adults
}

\author{
A. $\operatorname{Kaul}^{1}$, S. Gläser ${ }^{2}$, A. Hannemann ${ }^{1}$, C. Schäper ${ }^{2}$, M. Nauck ${ }^{1,3}$, S. B. Felix ${ }^{2,3}$, T. Bollmann ${ }^{2}$, R. Ewert ${ }^{2}$ and \\ N. Friedrich ${ }^{1,3 *}$ \\ ${ }^{1}$ Institute of Clinical Chemistry and Laboratory Medicine, University Medicine Greifswald, D-17475 Greifswald, Germany \\ ${ }^{2}$ Department of Internal Medicine B - Cardiology, Intensive Care, Pulmonary Medicine and Infectious Diseases, University \\ Medicine Greifswald, D-17475 Greifswald, Germany \\ ${ }^{3}$ German Centre for Cardiovascular Research (DZHK), Greifswald Partner Site, D-17475 Greifswald, Germany \\ (Submitted 27 July 2015 - Final revision received 2 October 2015 - Accepted 9 October 2015 - First published online 1 December 2015)
}

\section{Abstract}

Vitamin D has an important role in calcium homeostasis and is known to have various health-promoting effects. Moreover, potential interactions between vitamin $\mathrm{D}$ and physical activity have been suggested. This study aims to investigate the relationship between 25-hydroxyvitamin D (25(OH)D) and exercise capacity quantified by cardiopulmonary exercise testing (CPET). For this, 1377 participants from the Study of Health in Pomerania (SHIP-1) and 750 participants from the independent SHIP-TREND cohort were investigated. Standardised incremental exercise tests on a cycle ergometer were performed to assess exercise capacity by $\mathrm{VO}_{2}$ at anaerobic threshold, peakVO, $\mathrm{O}_{2}$ pulse and peak power output. Serum 25(OH)D levels were measured by an automated chemiluminescence immunoassay. In SHIP-1, 25(OH)D levels were positively associated with all considered parameters of cardiopulmonary exercise capacity. Subjects with high 25(OH)D levels (4th quartile) showed an up to $25 \%$ higher exercise capacity compared with subjects with low $25(\mathrm{OH}) \mathrm{D}$ levels (1st quartile). All associations were replicated in the independent SHIP-TREND cohort and were independent of age, sex, season and other interfering factors. In conclusion, significant positive associations between $25(\mathrm{OH}) \mathrm{D}$ and parameters of CPET were detected in two large cohorts of healthy adults.

Key words: Vitamin D: 25-Hydroxyvitamin D: Cardiopulmonary exercise capacity: Spiroergometry

Vitamin D, mainly synthesised in the skin under UV-B radiation exposure of 7-dehydrocholesterol, is transported to the liver and subsequently hydroxylated to 25 -hydroxyvitamin D $(25(\mathrm{OH}) \mathrm{D})^{(1)}$. Further, to a small extent food, for example, fish, eggs and milk, could be a source of vitamin D in the diet ${ }^{(2,3)} \cdot 25(\mathrm{OH}) \mathrm{D}$, the precursor of the active hormone calcitriol, has an important role in bone health ${ }^{(4-6)}$. During the past decade, several studies drew attention to vitamin D and its broad range of effects on health status and suggested that, besides the known effects on calcium homeostasis, vitamin D also could have an important role in CVD, cancer and autoimmune diseases ${ }^{(7)}$. However, the previously shown positive effects of vitamin D supplementation on fractures, tendency to fall or mortality ${ }^{(8-10)}$ are a matter of current controversies because recent studies partially repudiated these findings ${ }^{(11,12)}$. Thereby, given these inconsistencies, additional research with respect to vitamin D and its health effects is needed.

Few studies regarding the relation of vitamin D with physical performance have been conducted. Small studies among healthy subjects $^{(2-4,13-19)}$, mainly within a limited age range ${ }^{(2,3,13-19)}$, as well as studies among patients with congestive heart failure ${ }^{(20)}$, renal failure ${ }^{(21)}$ or chronic obstructive pulmonary disease $(\mathrm{COPD})^{(22,23)}$, revealed positive associations between vitamin D levels and measures of physical performance. In detail, vitamin D levels $>30 \mathrm{ng} / \mathrm{ml}$ were correlated to higher peakVO ${ }_{2}^{(2,13,14)}$, as shown by Mowry et al. $(r 0 \cdot 36 ; P<0 \cdot 01)^{(13)}$ and Ardestani et al. $(r 0.29 ; P<0.05)^{(14)}$, as well as static balance, gait speed or grip strength ${ }^{(3,4,15-19)}$, as assessed by Short Physical Performance Battery Tests (SPPBT).

Previous studies suggest various mechanisms potentially explaining the association between vitamin $\mathrm{D}$ and physical performance $^{(21,24-26)}$. Vitamin D appears to be involved in the function of muscle tissue ${ }^{(26)}$ by mainly influencing type II muscle fibres and binding to the $25(\mathrm{OH}) \mathrm{D}$ receptor, located in the muscle tissue. In addition, Ceglia et al. ${ }^{(24)}$ found an increase, even if non-significant, in intramyonuclear $25(\mathrm{OH}) \mathrm{D}$ receptor concentration in type I muscle fibres following supplementation

Abbreviations: $25(\mathrm{OH}) \mathrm{D}, 25$-hydroxyvitamin D; COPD, chronic obstructive pulmonary disease; CPET, cardiopulmonary exercise testing; peakVO 2 , highest 10 -s average of $\mathrm{VO}_{2}$ in the last minute of exercise; SHIP, Study of Health in Pomerania; SPPBT, Short Physical Performance Battery Tests; VO $@$ @AT, VO 2 at anaerobic threshold.

* Corresponding author: N. Friedrich, fax +49 3834 865502, email nele.friedrich@uni-greifswald.de 
of vitamin D in older mobility-limited vitamin D-insufficient women. Subsequently, the transcription of various genes is affected, and both ATP and muscle proteins are synthesised $^{(21,25)}$. In consequence, positive associations of increasing vitamin D levels with physical performance are probable.

The main limitation of previous studies among healthy subjects $^{(2,3,13-19)}$ is their limited age range, investigating either subjects younger than 25 years ${ }^{(2,13)}$ or older than 65 years ${ }^{(3,15-19)}$. A single study ${ }^{(14)}$ investigated a broader age range; however, the sample size of 200 subjects was relatively small. Therefore, the aim of our investigation was to examine the relationship between $25(\mathrm{OH}) \mathrm{D}$ levels and physical function parameters in a large population of subjects aged $25-85$ years and to replicate the findings in an independent sample. Physical function parameters including peakVO, $\mathrm{VO}_{2}$ at anaerobic threshold ( $\left.\mathrm{VO}_{2} @ \mathrm{AT}\right), \mathrm{O}_{2}$ pulse and maximum power output were assessed by cardiopulmonary exercise testing (CPET)

\section{Methods}

Study volunteers consisted of participants of the Study of Health in Pomerania (SHIP). SHIP is a population-based project in the northeast of Germany (latitude of $54^{\circ}$ North). The study details are given elsewhere ${ }^{(27,28)}$. In brief, from the entire study population of 212157 inhabitants living in the area, a sample was selected from the population registration offices, where all German inhabitants are registered. A two-stage cluster sampling method was adopted from the WHO MONICA (Multinational MONItoring of trends and determinants in CArdiovascular disease) Project Augsburg, Germany ${ }^{(28)}$. A representative sample was drawn, which comprised 7008 adults aged $20-79$ years with 292 persons of each sex in each of the twelve five-year age strata. The net sample (without migrated or deceased people) consisted of 6267 eligible subjects, of whom 4308 individuals eventually participated in the baseline study of SHIP (SHIP-0). Data collection started in October 1997 and was completed in March 2001. From March 2002 until July 2006, a five-year follow-up examination was performed (SHIP-1). The sample (without migrated, deceased or non-responding people) now comprised 3300 subjects (1584 men and 1709 women) aged 2585 years. Of those, 1708 subjects volunteered for a standardised progressive incremental exercise test on a cycle ergometer. The study conformed to the principles of the Declaration of Helsinki, as reflected by an a priori approval of the Ethics Committee of the University of Greifswald.

Among the 1708 subjects available for analyses, 274 subjects were excluded because of the presence of at least one of the following conditions: missing values of CPET parameters or $25(\mathrm{OH}) \mathrm{D}$ levels, parathyroid hormone $>120 \mathrm{pg} / \mathrm{ml}$, stenosis, estimated glomerular filtration rate $<30 \mathrm{ml} / \mathrm{min}$ per $1.73 \mathrm{~m}^{2}$, intake of digitalis glycosides (anatomical therapeutic chemical (ATC) code C01AA), selective Ca channel blockers with direct cardiac effects (ATC code C08D) or vitamin D and analogues (ATC code A11CC), as well as missing values for confounding factors. The final study population comprised 1377 individuals (677 men and 700 women).

To validate and to determine whether the findings from SHIP-1 can be generalised to other participants, data of the independent SHIP-TREND cohort were used for replication ${ }^{(17)}$. A representative (net) sample of 8826 adults aged 20-79 years was randomly selected from population registries into twentyfour age- and sex-specific strata. In total, 4420 subjects participated in the examination of SHIP-TREND between September 2008 and September 2012. There is no individual overlap with the first SHIP cohort. The study follows the recommendations of the Declaration of Helsinki and was approved by the Ethics Committee of the University of Greifswald. For a subsample of 1000 subjects, $25(\mathrm{OH}) \mathrm{D}$ measurements were available. The same exclusion criteria as described above were applied, resulting in a study population of 750 subjects ( 343 men and 407 women).

The selection process for both studies is displayed in online Supplementary Fig. S1.

\section{Measurements}

Information on age, sex, socio-demographic characteristics and medical histories was gained by computer-aided personal interviews. Smoking status and physical activity were assessed by self-report. Individuals who participated in physical training during summer or winter for at least $1 \mathrm{~h} /$ week were classified as being physically active. Waist circumference (WC) was measured to the nearest $0.1 \mathrm{~cm}$ using an inelastic tape midway between the lower rib margin and the iliac crest in the horizontal plane, with the subject standing comfortably with weight distributed evenly on both feet. The measurement was taken at the level of the narrowest part of the waist. All anthropometric measurements were taken in accordance with WHO standards.

Blood samples were drawn from the cubital vein in the supine position. The samples were taken between 07.00 and 16.00 hours, and serum aliquots were prepared for immediate analysis and for storage at $-80^{\circ} \mathrm{C}$. Serum $25(\mathrm{OH}) \mathrm{D}$ levels were measured on the IDS-iSYS Multi-Discipline Automated Analyzer (Immunodiagnostic Systems Limited). The CV were $16.8 \%$ at low $(12 \mathrm{ng} / \mathrm{ml}), 13.9 \%$ at medium $(30 \mathrm{ng} / \mathrm{ml})$ and $12.0 \%$ at high $(66 \mathrm{ng} / \mathrm{ml})$ concentrations in SHIP-1 and 11.6, 9.1 and 10.6\% concentrations in SHIP-TREND, respectively.

\section{Cardiopulmonary exercise testing and gas exchange variables}

A symptom-limited exercise test using one calibrated electromagnetically braked cycle ergometer with an electrical seat height adjustment (Ergoselect 100; Ergoline) was performed according to a modified Jones protocol (stepwise increase in work load of $16 \mathrm{~W} / \mathrm{min}$, starting with unloaded cycling plus the ergometer-related permanent load) ${ }^{(29)}$. Gas exchange and ventilatory variables were analysed breath by breath averaged over 10-s intervals using a computer-based system. Study details are given elsewhere ${ }^{(30)}$. In the absence of chest pain and electrocardiography (ECG) abnormalities, all tests were continued as symptom-limited (volitional exertion, dyspnoea or fatigue). Before the test, patients were encouraged to reach maximal exhaustion, whereas during exercise no further motivational interventions were used. All tests were performed at room temperature according to current guidelines for exercise testing, with continuous monitoring of ECG, blood pressure and $\mathrm{O}_{2}$ saturation $^{(31,32)}$. 
PeakVO 2 was defined as the highest 10-s average of $\mathrm{VO}_{2}$ in the last minute of exercise. The $\mathrm{VO}_{2} @ \mathrm{AT}$ was determined according to Wasserman et al. ${ }^{(33)}$. The determination of AT was based on non-invasive determination by gas exchange analysis by investigating the relationship of $\mathrm{VO}_{2}$ with $\mathrm{VCO}_{2}$ (V-slope method): end-tidal gas concentrations over time and ventilatory equivalents for $\mathrm{O}_{2}$ and carbon dioxide over time ${ }^{(33)}$. At least two of the three methods had to conform. Maximal power output was characterised as the highest reached power in Watt at the bicycle ergometer during exercise kept for at least $20 \mathrm{~s}$ at peakVO $\mathrm{N}_{2}$. All investigated parameters have been shown to be reliably reproducible ${ }^{(34,35)}$. Exercise duration was investigated from the start of exercise (without resting period) up to its termination.

\section{Statistical analysis}

Continuous data are expressed as medians and 25th; 75th percentiles. Nominal data are expressed as percentages. For bivariate analyses, the Kruskal-Wallis test (continuous data) or $\chi^{2}$ test (nominal data) was used to compare SHIP-1 and SHIP-TREND as well as men and women. ANOVA was carried out to calculate adjusted means for CPET parameters according to $25(\mathrm{OH}) \mathrm{D}$ categories (categorisation according to quartiles). Multivariable linear regression models were performed to estimate independent associations of $25(\mathrm{OH}) \mathrm{D}$ as continuous variable with CPET parameters. To detect possible non-linear associations, models with restricted cubic splines with three knots pre-specified located at the 5th, 50th and 95th percentile, as recommended by Stone \& $\mathrm{KoO}^{(36)}$, were compared by likelihood ratio test to the fit of the linear model. Normality or homogeneity of variance of the residuals was graphically checked by normal $\mathrm{Q}-\mathrm{Q}$ plot or by plotting the residuals $v$. predicted values, respectively. No violations against the assumptions were observed. The full models were adjusted for age, sex, weight, height, physical activity, smoking, time between core examination and pulmonary function testing and month of blood sampling. A value of $P<0.05$ was considered statistically significant. Statistical analyses were performed with SAS 9.3 (SAS Institute Inc.).

\section{Results}

Both study populations were comparable with regard to the sex distribution, whereas SHIP-1 participants were more often smokers and had a higher WC than SHIP-TREND participants (Table 1). Furthermore, SHIP-1 individuals had lower peakVO and maximum power output values than SHIP-TREND individuals. With respect to $25(\mathrm{OH})$ D levels, SHIP-1 participants had on average $6 \mathrm{ng} / \mathrm{ml}$ lower values than SHIP-TREND participants. In both study populations, a clear seasonal variation in 25(OH)D level was observed (Fig. 1), with highest values in late summer through fall (August-October).

ANOVA revealed significant positive associations between 25(OH)D levels and all considered CPET parameters in both the SHIP-1 and the SHIP-TREND populations (Fig. 2). In SHIP-1, estimated peakVO $\mathrm{VO}_{2} @ \mathrm{AT}, \mathrm{O}_{2}$ pulse and maximum power output were $140 \mathrm{ml} / \mathrm{min}, 70 \mathrm{ml} / \mathrm{min}, 0.85 \mathrm{ml}$ and $13 \mathrm{~W}$ higher in the fourth compared with the first 25(OH)D quartile $(P<0.05$ for all outcomes), respectively. The same results were observed in SHIP-TREND with $220 \mathrm{ml} / \mathrm{min}, 120 \mathrm{ml} / \mathrm{min}, 1.3 \mathrm{ml}$ and $17 \mathrm{~W}$ higher estimated values of peakVO $, \mathrm{VO}_{2} @ \mathrm{AT}, \mathrm{O}_{2}$ pulse and maximum power output in the fourth compared with the first $25(\mathrm{OH}) \mathrm{D}$ quartile $(P<0.05$ for all outcomes), respectively. Linear regression analyses confirmed the ANOVA findings (Table 2, Fig. 3). Again, increasing 25(OH)D levels are accompanied by strong increasing values of peakVO, $\mathrm{VO}_{2} @ \mathrm{AT}$, $\mathrm{O}_{2}$ pulse and maximum power output in SHIP-TREND. In SHIP-1, strong positive associations with peakVO $\mathrm{VO}_{2}$ and $\mathrm{VO}_{2} @ \mathrm{AT}$ were observed. With regard to $\mathrm{O}_{2}$ pulse and maximum power output, non-linear relations were detected. Whereas an increase in $25(\mathrm{OH}) \mathrm{D}$ levels up to $27 \mathrm{ng} / \mathrm{ml}$ was related to a strong increase in $\mathrm{O}_{2}$ pulse and maximum power output, 25(OH)D levels $>27 \mathrm{ng} / \mathrm{ml}$ were only associated with a small rise in both parameters (Fig. 3).

To assess whether the presence of co-morbidities affected the associations between 25(OH)D levels and CPET parameters, we further adjusted all models for high blood pressure (systolic $>140 \mathrm{mmHg}$ or diastolic $>90 \mathrm{mmHg}$ ), total cholesterol, glycated $\mathrm{Hb}$ and estimated glomerular filtration rate. All additional analyses confirmed the above-mentioned results, with nearly no changes in the estimates (data not shown). Furthermore, linear regression analyses were performed separately for men and women (online Supplementary Table S1, Fig. S2 and S3). The detected strong positive associations between 25 $(\mathrm{OH}) \mathrm{D}$ and peakVO $, \mathrm{VO}_{2} @ \mathrm{AT}, \mathrm{O}_{2}$ pulse or maximum power were confirmed among men in both study populations and among women participating in SHIP-TREND. Among women in SHIP-1, only maximum power remained significant.

\section{Discussion}

Over the last decade, increasing attention has been given to vitamin $\mathrm{D}$ and its broad range of effects on health status. Recent clinical and experimental studies suggest that vitamin D in addition to its crucial function in bone metabolism also could have an important role in the pathogenesis of CVD, cancer and autoimmune diseases ${ }^{(7)}$. These findings, together with the world-wide high prevalence of vitamin D deficiency, might represent a major economic burden on the health system $^{(37)}$. However, the positive effects shown by some meta-analyses or randomised controlled trials of vitamin $\mathrm{D}$ supplementation on fractures, tendency to fall or mortality ${ }^{(8-10)}$ are currently a subject of controversial discussion because of the fact that recent studies partially repudiated these findings ${ }^{(11,12)}$. Given the inconsistencies regarding the benefit of vitamin $\mathrm{D}$ on health status, additional research is needed. Few studies exploring the relationship between vitamin $\mathrm{D}$ and exercise capacity have been conducted. To our knowledge, this is the first crosssectional study investigating the relationship between 25(OH)D levels and exercise capacity in two large studies of the general population with a broad age range of $25-85$ years.

Former studies focused either on small groups of healthy volunteers with young ${ }^{(2,13)}$ or old ${ }^{(3,15-19,38)}$ subjects, as well as clinical cohorts ${ }^{(20-23)}$. Our analyses revealed significant positive relations between 25(OH)D levels and CPET parameters including peakVO, $\mathrm{VO}_{2} @ \mathrm{AT}$, maximum power output and 
Table 1. Descriptive statistics of the study populations ${ }^{\star}$

(Medians and 25th; 75th percentiles; percentages)

\begin{tabular}{|c|c|c|c|c|c|c|c|c|c|c|c|c|c|c|c|}
\hline \multirow[b]{3}{*}{ Characteristics } & \multirow{2}{*}{\multicolumn{2}{|c|}{ SHIP-1 }} & \multirow{2}{*}{\multicolumn{2}{|c|}{ SHIP-TREND }} & \multirow[b]{3}{*}{$P$} & \multicolumn{5}{|c|}{ SHIP-1 } & \multicolumn{5}{|c|}{ SHIP-TREND } \\
\hline & & & & & & \multicolumn{2}{|r|}{ Men } & \multicolumn{2}{|c|}{ Women } & \multirow[b]{2}{*}{$P$} & \multicolumn{2}{|r|}{ Men } & \multicolumn{2}{|c|}{ Women } & \multirow[b]{2}{*}{$P$} \\
\hline & Median & $\begin{array}{l}\text { 25th; } 75 \text { th } \\
\text { percentiles }\end{array}$ & Median & $\begin{array}{l}\text { 25th; } 75 \text { th } \\
\text { percentiles }\end{array}$ & & Median & $\begin{array}{l}25 \text { th; } 75 \text { th } \\
\text { percentiles }\end{array}$ & Median & $\begin{array}{l}\text { 25th; } 75 \text { th } \\
\text { percentiles }\end{array}$ & & Median & $\begin{array}{l}\text { 25th; } 75 \text { th } \\
\text { percentiles }\end{array}$ & Median & $\begin{array}{l}\text { 25th; } 75 \text { th } \\
\text { percentiles }\end{array}$ & \\
\hline$n$ & \multicolumn{2}{|r|}{1377} & \multicolumn{2}{|r|}{750} & - & \multicolumn{2}{|r|}{677} & \multicolumn{2}{|r|}{700} & - & \multicolumn{2}{|r|}{343} & \multicolumn{2}{|r|}{407} & - \\
\hline Age (years) $\dagger$ & 52 & $41 ; 62$ & 51 & $41 ; 61$ & 0.30 & 52 & $41 ; 63$ & 51 & $41 ; 61$ & 0.04 & 51 & $41 ; 61$ & 52 & $41 ; 61$ & 0.55 \\
\hline Men (\%) & & $49 \cdot 2$ & & $45 \cdot 2$ & 0.13 & & - & & - & - & & - & & - & - \\
\hline Smoking (\%) & & & & & $<0.01$ & & & & & $<0.01$ & & & & & $<0.01$ \\
\hline Never smokers & & $43 \cdot 6$ & & $42 \cdot 4$ & & & $30 \cdot 3$ & & $56 \cdot 4$ & & & 31.8 & & 51.4 & \\
\hline Former smokers & & $32 \cdot 1$ & & 37.9 & & & $45 \cdot 2$ & & 19.4 & & & 48.4 & & $29 \cdot 0$ & \\
\hline Current smokers & & $24 \cdot 3$ & & 19.7 & & & 24.5 & & 24.1 & & & 19.8 & & 19.7 & \\
\hline Physical activity (\%) & & $44 \cdot 9$ & & 74.4 & $<0.01$ & & $41 \cdot 8$ & & 47.9 & 0.02 & & 73.2 & & $75 \cdot 4$ & 0.48 \\
\hline Weight (kg) & $78 \cdot 9$ & $68 \cdot 7 ; 90 \cdot 2$ & $77 \cdot 6$ & $67 \cdot 4 ; 89 \cdot 2$ & $0 \cdot 14$ & $85 \cdot 6$ & $77 \cdot 2 ; 95 \cdot 8$ & $70 \cdot 8$ & $62 \cdot 6 ; 81 \cdot 7$ & $<0.01$ & $86 \cdot 4$ & $77 \cdot 3 ; 96 \cdot 2$ & $70 \cdot 0$ & $62 \cdot 6 ; 80 \cdot 0$ & $<0.01$ \\
\hline Height $(\mathrm{cm})$ & 169 & $163 ; 177$ & 170 & $163 ; 177$ & 0.76 & 176 & $171 ; 180$ & 164 & $160 ; 168$ & $<0.01$ & 177 & $173 ; 180$ & 165 & $160 ; 169$ & $<0.01$ \\
\hline Waist circumference $(\mathrm{cm})$ & 92 & $82 ; 101$ & 87 & $79 ; 97$ & $<0.01$ & 97 & $90 ; 105$ & 85 & $76 ; 94$ & $<0.01$ & 95 & $87 ; 102$ & 81 & $74 ; 90$ & $<0.01$ \\
\hline 25(OH)D (ng/ml) & $18 \cdot 3$ & $13 \cdot 1 ; 25 \cdot 4$ & 24.6 & $17 \cdot 4 ; 32 \cdot 6$ & $<0.01$ & $18 \cdot 1$ & $13 \cdot 4 ; 24 \cdot 8$ & 18.5 & $12 \cdot 8 ; 25 \cdot 9$ & 0.60 & 24.5 & $18 \cdot 1 ; 32 \cdot 2$ & $24 \cdot 7$ & $16 \cdot 6 ; 32 \cdot 8$ & 0.61 \\
\hline $\mathrm{PeakVO}_{2}(\mathrm{ml} / \mathrm{min})$ & 1880 & $1538 ; 2371$ & 1952 & $1572 ; 2537$ & 0.01 & 2328 & $1950 ; 2750$ & 1600 & $1400 ; 1808$ & $<0.01$ & 2569 & $2174 ; 2993$ & 1600 & $1400 ; 100$ & $<0.01$ \\
\hline $\mathrm{VO}_{2} @ \mathrm{AT}(\mathrm{ml} / \mathrm{min})$ & 1050 & $900 ; 1300$ & 1000 & $800 ; 1200$ & $<0.01$ & 1200 & $1050 ; 1450$ & 950 & $800 ; 1100$ & $<0.01$ & 1200 & $1000 ; 1400$ & 850 & $800 ; 1000$ & $<0.01$ \\
\hline $\mathrm{O}_{2}$ pulse $(\mathrm{ml})$ & $12 \cdot 9$ & $10 \cdot 6 ; 15 \cdot 7$ & $12 \cdot 8$ & $10 \cdot 4 ; 15 \cdot 8$ & 0.50 & $15 \cdot 6$ & $13 \cdot 6 ; 17 \cdot 9$ & $10 \cdot 7$ & $9 \cdot 6 ; 12 \cdot 1$ & $<0.01$ & $16 \cdot 0$ & $14 \cdot 3 ; 18 \cdot 1$ & $10 \cdot 7$ & $9 \cdot 2 ; 12 \cdot 0$ & $<0.01$ \\
\hline Maximum power output (W) & 148 & $116 ; 180$ & 164 & $132 ; 196$ & $<0.01$ & 180 & $148 ; 212$ & 116 & $100 ; 148$ & $<0.01$ & 196 & $180 ; 228$ & 132 & $116 ; 148$ & $<0.01$ \\
\hline
\end{tabular}

SHIP, Study of Health in Pomerania; 25(OH)D, 25-hydroxyvitamin D; peakVO ${ }_{2}$, highest 10-s average of $\mathrm{VO}_{2}$ in the last minute of exercise; $\mathrm{VO}_{2} @ \mathrm{AT}, \mathrm{VO}_{2}$ at anaerobic threshold.

${ }^{*} \chi^{2}$ Test (nominal data) or Kruskal-Wallis test (interval data) was used to compare SHIP-1 and SHIP-TREND or men and women.

† Age at core examination. 
$\mathrm{O}_{2}$ pulse in SHIP-1. These results were replicated in SHIP-TREND - a second independent large population.

Previous studies, investigating the association between 25(OH)D levels and physical performance, either used CPET or alternative methods - for example, the SPPBT. In concordance with our results regarding peakVO${ }_{2}{ }^{(2,13,14)}$ positive correlations between 25(OH)D levels and aerobic-exercise capacity quantified by $\mathrm{VO}_{2 \max }$ or by treadmill test ${ }^{(2,13,14)}$ were found. Although the above-mentioned studies have measured the relative $\mathrm{VO}_{2 \text { max }}$, our study focused on the peakVO . The peakVO $\mathrm{O}_{2}$ indicates the amount of $\mathrm{O}_{2}$ that can be absorbed by the body per min, whereas the relative $\mathrm{VO}_{2 \max }$ indicates the $\mathrm{O}_{2}$ absorption in relation to the body weight of the respective subjects. However, because of the fact that all presented statistical analyses were adjusted, among others factors, for both the body size and weight, the results reflect the same issue. Unfortunately, only one of these studies performed sex-specific analyses $^{(2)}$ and detected an association between 25(OH)D and peak $\mathrm{VO}_{2}$ in men but not in women. In the present study,

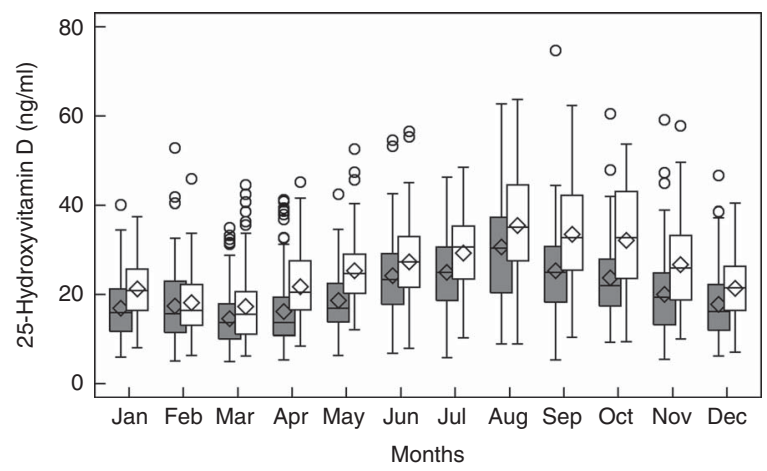

Fig. 1. Boxplots of 25-hydroxyvitamin $D$ levels by month in the Study of Health in Pomerania $(\square$, SHIP-1) and SHIP-TREND $(\square)$ populations.
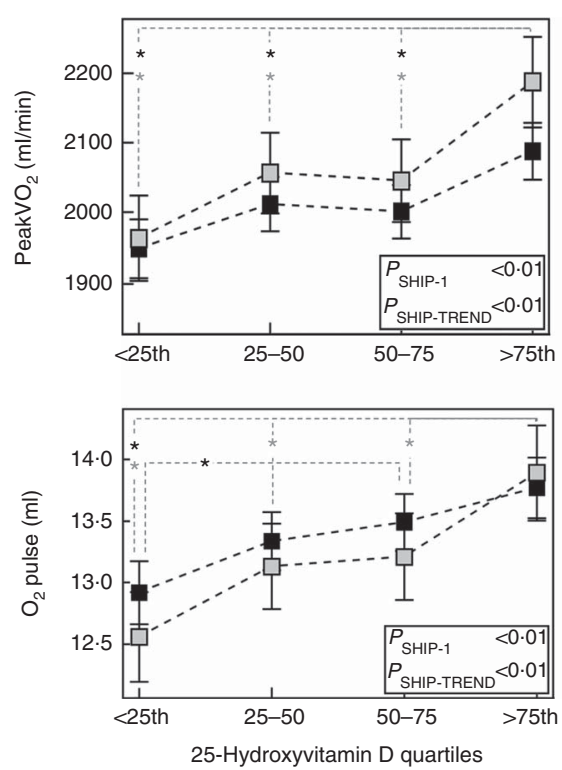

however, sex-specific analyses showed a positive association in both sexes. One possible explanation might be the relatively low number of included subjects ( $n 19$ women) in the previously performed study ${ }^{(2)}$.

The present study also showed significant positive associations between 25(OH)D and $\mathrm{VO}_{2} @ \mathrm{AT}$, maximum power output, as well as $\mathrm{O}_{2}$ pulse. In contrast to these findings, one previous study $^{(2)}$, among thirty-nine healthy subjects, found no differences in anaerobic power or strength parameters including bench press, leg curl, leg extension or vertical jump in relation to $25(\mathrm{OH}) \mathrm{D}$ status. The different sample sizes and investigation methods might be reasons for the inconsistent results ${ }^{(2)}$.

Further studies using the SPPBT, as well as static balance, gait speed or grip strength ${ }^{(3,4,15-19)}$, showed consistently positive associations between $25(\mathrm{OH}) \mathrm{D}$ levels and physical performance in healthy volunteers. Only one study examining 367 subjects with a mean age of 84.7 years did not confirm the above-mentioned results and revealed no relation between $25(\mathrm{OH}) \mathrm{D}$ and gait speed, grip strength or balance ${ }^{(3)}$. A possible explanation might be the older age of the study population.

In addition to the above-mentioned studies among healthy subjects, there are also few investigations among patients with congestive heart failure ${ }^{(20)}$, renal failure ${ }^{(21)}$ or $\operatorname{COPD}^{(22,23)}$. Among patients with renal failure ${ }^{(21)}$ or $\mathrm{COPD}^{(23)}$, positive associations between 25(OH)D levels and peakVO $\mathrm{V}_{2}$ determined by treadmill testing ${ }^{(21)}$ or bicycle ergometer ${ }^{(23)}$ were observed. In addition, among forty subjects with heart failure ${ }^{(20)}, 25(\mathrm{OH}) \mathrm{D}$ levels were positively related to peakVO $\mathrm{VO}_{2}$. However, in the latter study, no association between $25(\mathrm{OH}) \mathrm{D}$ levels and muscle strength as a key factor of physical performance became apparent. The authors concluded that randomised controlled trials are needed to assess the effect of vitamin D on physical performance ${ }^{(20)}$. In the following, the effect of vitamin D administration on SPPBT was examined over a period of 6 weeks
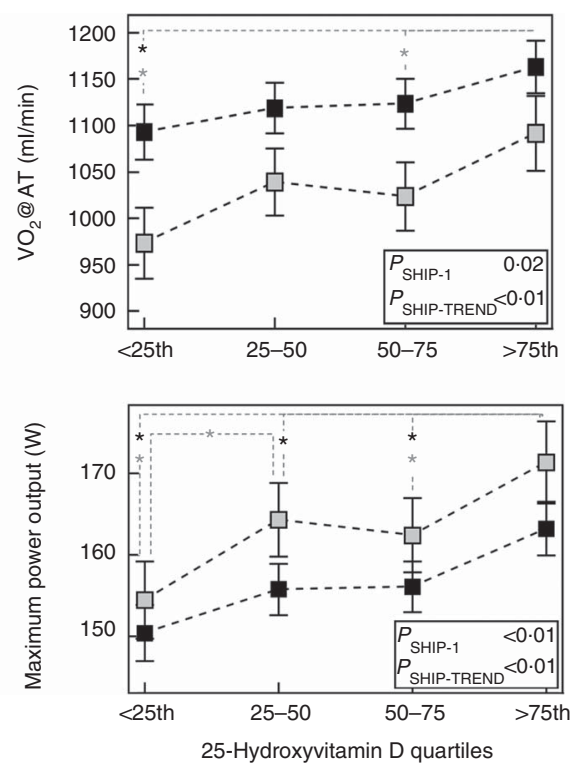

Fig. 2. Estimated mean levels of highest 10-s average of $\mathrm{VO}_{2}$ in the last minute of exercise (peakVO $\left.\mathrm{O}_{2}\right), \mathrm{VO}_{2}$ at anaerobic threshold $\left(\mathrm{VO}_{2} @ \mathrm{AT}\right), \mathrm{O}_{2}$ pulse and maximum power output with $95 \% \mathrm{Cl}$ by quartiles of 25-hydroxyvitamin D in the Study of Health in Pomerania ( $\square$, SHIP-1) and SHIP-TREND ( $\square$ ) populations. ANOVA were adjusted for age, sex, weight, height, physical activity, smoking, time between core examination and pulmonary function testing and month of blood sampling. Pair-wise comparisons were performed using the Tukey-Kramer method for multiple comparison adjustment (SHIP-1: ${ }^{*} P<0.05$; SHIP-TREND: * $P<0.05$ ). 
among thirty-six male COPD patients with a mean age of 68 years $^{(22)}$. Even though an increase in mean levels of $25(\mathrm{OH}) \mathrm{D}$ from 22.6 to $32.6 \mathrm{ng} / \mathrm{ml}$ was observed, no change in the SPPBT score was found, which led to the conclusion that vitamin D supplementation has no notable influence on physical performance ${ }^{(22)}$.

With respect to the testing methods, the majority of the mentioned studies among healthy subjects ${ }^{(3,4,15-19,38)}$, as well as the study among COPD patients ${ }^{(22)}$, applied testing methods (static balance, gait speed, grip strength, surveys) that do not provide information on performance parameters (peakVO $\mathrm{V}_{2}$, $\mathrm{VO}_{2} @ \mathrm{AT}, \mathrm{O}_{2}$ pulse, maximum power output). All of these test methods, which are common practice in predominantly geriatric patients, focus mainly on balance and interpret the muscle strength in the lower extremities but do not provide information about endurance capacity. Given the methodological differences used to assess physical performance (SPPBT, treadmill testing or bicycle ergometer) in previous studies, caution should be used when interpreting and comparing results across studies. The use of $\mathrm{CPET}^{(2,13,14,20,23)}$ reflects the function of balance or muscle strength in the lower extremities, and it also provides information on the cardiovascular and respiratory system and thus represents a benchmark for physical performance ${ }^{(39)}$. The only study investigating ${ }^{(22)}$ the influence of vitamin D supplementation on physical performance used the SPPBT and did not find any positive effect. However, future studies using CPET are needed to draw conclusions on the effect of vitamin D supplementation on physical performance.

There are several possible explanatory approaches for the positive relation of $25(\mathrm{OH}) \mathrm{D}$ levels and exercise capacity: a first explanation might be that subjects with high 25(OH)D levels spend their leisure time actively outside and are therefore more physically active. However, it must be also noted that people who spend a lot of time outdoors can still suffer from a lack of $25(\mathrm{OH}) \mathrm{D}$ because of the use of sunscreen. Nevertheless, outdoors the UV exposition is higher and sunscreen does not provide $100 \%$ UV protection, but merely extends the selfprotection time of the skin in the sun. A second explanation might be seen in the role of $25(\mathrm{OH}) \mathrm{D}$ in the musculoskeletal system $^{(25)}$. A sufficient vitamin D supply likely optimises the work of type II muscle fibres, which are responsible for maximal physical endurance ${ }^{(4,25)}$. Finally, a study reported that the vitamin D receptor (VDR) is present in human muscle tissue $^{(4)} \cdot 25(\mathrm{OH}) \mathrm{D}$ binds to the VDR, which eventually leads to a de novo protein and muscle synthesis ${ }^{(22)}$, as well as the transcription of $\mathrm{ATP}^{(21,25)}$ - both being important factors for physical performance. Therefore, it is possible that subjects with higher $25(\mathrm{OH}) \mathrm{D}$ levels accomplish a better performance by improved muscular work than vitamin D-deficient subjects.

During the past decades, several investigations proved that physical activity and exercise capacity represent independent predictors of mortality. These findings were mainly observed in large patient cohorts including subjects, for example, with coronary artery disease ${ }^{(40)}, \mathrm{CVD}^{(41)}$, type 2 diabetes mellitus ${ }^{(42)}$ or cardiopulmonary disease ${ }^{(43)}$. However, also in subjects without CVD, a low exercise capacity was related to a higher mortality risk as for example, shown among 2534 individuals with normal exercise-test result and no history of $\mathrm{CVD}^{(41)}$, 506 veterans 

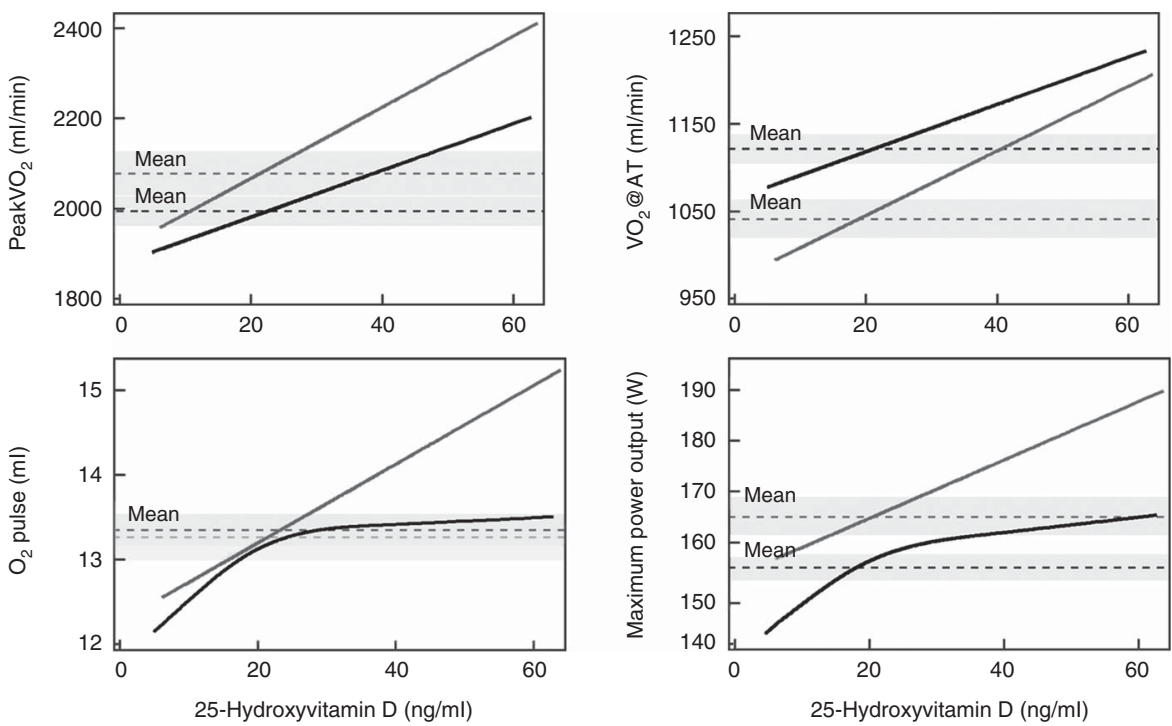

Fig. 3. Predicted mean of highest 10-s average of $\mathrm{VO}_{2}$ in the last minute of exercise (peakVO $\left.\mathrm{O}_{2}\right), \mathrm{VO}_{2}$ at anaerobic threshold $\left(\mathrm{VO}_{2} @ A T\right), \mathrm{O}_{2}$ pulse and maximum power output depending on 25-hydroxyvitamin D levels for the Study of Health in Pomerania $(-,-$ SHIP-1) and SHIP-TREND $(-)$ populations calculated by linear regression analyses with restricted cubic splines. Models were adjusted for age, sex, weight, height, physical activity, smoking, time between core examination and pulmonary function testing and month of blood sampling.

without cardiopulmonary disease ${ }^{(43)}$ or 44691 subjects without hypertension ${ }^{(44)}$. Even if these studies were based on different methods to assess exercise capacity (treadmill or cycle ergometer) and used different parameters such as peakVO ${ }^{(40,42,43)}$, treadmill time ${ }^{(44)}$ or metabolic equivalents ${ }^{(41)}$, the findings clearly showed that exercise capacity is a powerful predictor of CVD and mortality. Therefore, a preserved exercise capacity in patients with CVD, as well as the general population, might be a useful tool to decrease CVD morbidity and to improve mortality.

The major strength of the present study represents the large number of subjects investigated within a highly standardised setting. In addition, we succeeded in replicating the findings in an independent large population. The technique applied for physical performance testing demonstrates a further strength. In contrast to former studies using treadmill stress testing for example, we were able to investigate additional parameters beyond peakVO $\mathrm{V}_{2}$, including $\mathrm{VO}_{2} @ \mathrm{AT}, \mathrm{O}_{2}$ pulse and maximum power. Nevertheless, our study is limited by its cross-sectional design, which is not suitable to prove causal relations. Even if a statistically significant association between 25(OH)D and exercise capacity cannot be denied on the basis of our results, however, longitudinal studies, as well as interventional studies, are particularly necessary in order to prove that $25(\mathrm{OH}) \mathrm{D}$ is causally associated with exercise capacity. Furthermore, limitations that should be taken into account by the interpretation of the present study are that factors such as nutritional habits, which might influence the $25(\mathrm{OH}) \mathrm{D}$ levels as shown before $^{(45)}$, were not considered because of the lack of reliable data and the partly high $\mathrm{CV}$ of the $25(\mathrm{OH}) \mathrm{D}$ assay used.

In conclusion, although the exact mechanism remains undetermined to some degree, in the present study we detected positive associations between $25(\mathrm{OH}) \mathrm{D}$ levels and parameters of physical performance among healthy subjects over a broad age range and replicated the results in an independent population. Interventional studies are needed to investigate whether vitamin D supplementation leads to improvement in physical performance and therefore could contribute to health care in the general population.

\section{Acknowledgements}

This work was funded by grants from the German Federal Ministry of Education and Research (BMBF, grants 01ZZ0403, 01ZZ0103, 01GI0883), the Ministry for Education, Research and Cultural Affairs, as well as the Ministry of Social Affairs of the Federal State of Mecklenburg-West Pomerania. This work is also part of the research project Greifswald Approach to Individualized Medicine (GANI_MED). The GANI_MED consortium is funded by the Federal Ministry of Education and Research and the Ministry of Cultural Affairs of the Federal State of Mecklenburg-West Pomerania (03IS2061A).

Formulating the research question: A. K., N. F.; designing the study: M. N., S. B. F., R. E.; conducting the study: S. G., T. B., C. S.; data analysis: N. F.; writing the article: A. K., S. G., A. H., N. F.

The authors declare that there are no conflicts of interest.

\section{Supplementary material}

For supplementary material/s referred to in this article, please visit http://dx.doi.org/doi:10.1017/S000711451500464X

\section{References}

1. Finklea JD, Grossmann RE \& Tangpricha V (2011) Vitamin D and chronic lung disease: a review of molecular mechanisms and clinical studies. Adv Nutr 2, 244-253.

2. Forney LA, Earnest CP, Henagan TM, et al. (2014) Vitamin D status, body composition, and fitness measures in collegeaged students. J Strength Cond Res 28, 814-824. 
3. Mathei C, Van Pottelbergh G, Vaes B, et al. (2013) No relation between vitamin $\mathrm{D}$ status and physical performance in the oldest old: results from the Belfrail study. Age Ageing $\mathbf{4 2}$, 186-190.

4. Ceglia L (2008) Vitamin D and skeletal muscle tissue and function. Mol Aspects Med 29, 407-414.

5. Christodoulou S, Goula T, Ververidis A, et al. (2013) Vitamin D and bone disease. Biomed Res Int 2013, 396541.

6. Zittermann A \& Gummert JF (2010) Nonclassical vitamin D action. Nutrients 2, 408-425.

7. Guessous I (2015) Role of vitamin D deficiency in extraskeletal complications: predictor of health outcome or marker of health status? Biomed Res Int 2015, 563403.

8. Bischoff-Ferrari HA, Dawson-Hughes B, Staehelin HB, et al. (2009) Fall prevention with supplemental and active forms of vitamin D: a meta-analysis of randomised controlled trials. BMJ 339, b3692.

9. Zheng Z, Shi H, Jia J, et al. (2013) Vitamin D supplementation and mortality risk in chronic kidney disease: a meta-analysis of 20 observational studies. BMC Nephrol 14, 199.

10. Pludowski P, Holick MF, Pilz S, et al. (2013) Vitamin D effects on musculoskeletal health, immunity, autoimmunity, cardiovascular disease, cancer, fertility, pregnancy, dementia and mortality - a review of recent evidence. Autoimmun Rev $\mathbf{1 2}$, 976-989.

11. Bolland MJ, Grey A, Gamble GD, et al. (2014) The effect of vitamin D supplementation on skeletal, vascular, or cancer outcomes - authors' reply. Lancet Diabetes Endocrinol 2, 364-365.

12. Theodoratou E, Tzoulaki I, Zgaga L, et al. (2014) Vitamin D and multiple health outcomes: umbrella review of systematic reviews and meta-analyses of observational studies and randomised trials. BMJ 348, g2035.

13. Mowry DA, Costello MM \& Heelan KA (2009) Association among cardiorespiratory fitness, body fat, and bone marker measurements in healthy young females. J Am Osteopath Assoc 109, 534-539.

14. Ardestani A, Parker B, Mathur S, et al. (2011) Relation of vitamin $\mathrm{D}$ level to maximal oxygen uptake in adults. $A m \mathrm{~J}$ Cardiol 107, 1246-1249.

15. Houston DK, Cesari M, Ferrucci L, et al. (2007) Association between vitamin $\mathrm{D}$ status and physical performance: the InCHIANTI study. J Gerontol A Biol Sci Med Sci 62, 440-446.

16. Houston DK, Tooze JA, Hausman DB, et al. (2011) Change in 25-hydroxyvitamin $\mathrm{D}$ and physical performance in older adults. J Gerontol A Biol Sci Med Sci 66, 430-436.

17. Houston DK, Tooze JA, Neiberg RH, et al. (2012) 25-hydroxyvitamin D status and change in physical performance and strength in older adults: the Health, Aging, and Body Composition Study. Am J Epidemiol 176, 1025-1034.

18. Michael YL, Smit E, Seguin R, et al. (2011) Serum 25-hydroxyvitamin $\mathrm{D}$ and physical performance in postmenopausal women. J Womens Health (Larchmt) 20, 1603-1608.

19. Toffanello ED, Perissinotto E, Sergi G, et al. (2012) Vitamin D and physical performance in elderly subjects: the Pro.V. A study. PLOS ONE 7, e34950.

20. Boxer RS, Kenny AM, Cheruvu VK, et al. (2010) Serum 25-hydroxyvitamin D concentration is associated with functional capacity in older adults with heart failure. Am Heart J 160, 893-899.

21. Petchey WG, Howden EJ, Johnson DW, et al. (2011) Cardiorespiratory fitness is independently associated with 25-hydroxyvitamin D in chronic kidney disease. Clin J Am Soc Nephrol 6, 512-518.
22. Bjerk SM, Edgington BD, Rector TS, et al. (2013) Supplemental vitamin $\mathrm{D}$ and physical performance in COPD: a pilot randomized trial. Int J Chron Obstruct Pulmon Dis $\mathbf{8}$, 97-104.

23. Ferrari M, Schenk K, Papadopoulou C, et al. (2011) Serum 25-hydroxy vitamin D and exercise capacity in COPD. Thorax 66, 544-545.

24. Ceglia L, Niramitmahapanya S, da Silva Morais M, et al. (2013) A randomized study on the effect of vitamin $\mathrm{D}(3)$ supplementation on skeletal muscle morphology and vitamin D receptor concentration in older women. J Clin Endocrinol Metab 98, E1927-E1935.

25. Shuler FD, Wingate MK, Moore GH, et al. (2012) Sports health benefits of vitamin D. Sports Health 4, 496-501.

26. Hamilton B (2011) Vitamin D and athletic performance: the potential role of muscle. Asian J Sports Med 2, 211-219.

27. Völzke H, Alte D, Schmidt CO, et al. (2011) Cohort profile: the study of health in Pomerania. Int J Epidemiol 40, 294-307.

28. Keil U, Stieber J, Doring A, et al. (1988) The cardiovascular risk factor profile in the study area Augsburg. Results from the first MONICA survey 1984/85. Acta Med Scand Suppl 728, 119-128.

29. Jones NL, Makrides L, Hitchcock C, et al. (1985) Normal standards for an incremental progressive cycle ergometer test. Am Rev Respir Dis 131, 700-708.

30. Koch B, Schaper C, Ittermann T, et al. (2009) Reference values for cardiopulmonary exercise testing in healthy volunteers: the SHIP study. Eur Respir J 33, 389-397.

31. American Thoracic Society; American College of Chest Physicians (2003) ATS/ACCP statement on cardiopulmonary exercise testing. Am J Respir Crit Care Med 167, 211-277.

32. Palange P, Ward SA, Carlsen KH, et al. (2007) Recommendations on the use of exercise testing in clinical practice. Eur Respir J 29, 185-209.

33. Wasserman K, Hansen JE, Sue DY, et al. (2004) Principles of Exercise Testing and Interpretation: Including Pathophysiology and Clinical Applications, 4th ed. Philadelphia, PA: Lippincott Williams and Wilkins.

34. Meyer K, Westbrook S, Schwaibold M, et al. (1997) Short-term reproducibility of cardiopulmonary measurements during exercise testing in patients with severe chronic heart failure. Am Heart J 134, 20-26.

35. Van Laethem C, De Sutter J, Peersman W, et al. (2009) Intratest reliability and test-retest reproducibility of the oxygen uptake efficiency slope in healthy participants. Eur J Cardiovasc Prev Rehabil 16, 493-498.

36. Stone C \& Koo CY (1985) Additive splines in statistics. In Proceedings of the Statistical Computing Section, pp. 45-48. Washington, DC: American Statistical Association.

37. Grant WB, Schwalfenberg GK, Genuis SJ, et al. (2010) An estimate of the economic burden and premature deaths due to vitamin D deficiency in Canada. Mol Nutr Food Res 54, 1172-1181.

38. Dam TT, von Muhlen D \& Barrett-Connor EL (2009) Sex-specific association of serum vitamin D levels with physical function in older adults. Osteoporos Int 20, 751-760.

39. Walker HK, Hall WD \& Hurst JW (1990) Clinical Methods: The History, Physical and Laboratory Examinations, 3rd ed. Boston, MA and London: Butterworths.

40. Coeckelberghs E, Buys R, Goetschalckx K, et al. (2015) Prognostic value of the oxygen uptake efficiency slope and other exercise variables in patients with coronary artery disease. Eur J Prev Cardiol (epublication ahead of print version 29 January 2015).

41. Myers J, Prakash M, Froelicher V, et al. (2002) Exercise capacity and mortality among men referred for exercise testing. $N$ Engl J Med 346, 793-801. 
42. Seyoum B, Estacio RO, Berhanu P, et al. (2006) Exercise capacity is a predictor of cardiovascular events in patients with type 2 diabetes mellitus. Diab Vasc Dis Res 3, 197-201.

43. Oliveira RB, Myers J, Araujo CG, et al. (2009) Maximal exercise oxygen pulse as a predictor of mortality among male veterans referred for exercise testing. Eur J Cardiovasc Prev Rehabil 16, 358-364.
44. Vigen R, Ayers C, Willis B, et al. (2012) Association of cardiorespiratory fitness with total, cardiovascular, and noncardiovascular mortality across 3 decades of follow-up in men and women. Circ Cardiovasc Qual Outcomes 5, 358-364.

45. Joh HK, Lim CS \& Cho B (2015) Lifestyle and dietary factors associated with serum 25-hydroxyvitamin D levels in Korean young adults. J Korean Med Sci 30, 1110-1120. 